\title{
Toward the Development of a Mobile Studio Environment
}

\author{
Don Millard, Mohamed Chouikha
}

\author{
Rensselaer/Howard University
}

\begin{abstract}
This paper presents an overview of Rensselaer's "mobile studio" engineering teaching environment that is currently being used in circuits and electronics courses designed for college sophomores and juniors. The paper discusses the deployment of HP Tablet PCs along with mobile technologies at Rensselaer and Howard University to: 1) eliminate the boundaries between the theory and fundamentals provided in a lecture; 2) help students apply theoretical concepts in directed problem sessions; and 3) enable exploration of engineering principles, devices, and systems that have historically been restricted to specific laboratory facilities. The paper's presentation will demonstrate the pedagogical practices, the interactive materials, and accompanying hardware/software that turn the Tablet PC into a mobile laboratory suite integrating a function generator, multimeter, $5 \mathrm{v}$ power supply, and scope. A description of the initial pilot project deployment is provided along with an explanation of how the student's laboratory results will be integrated into a WebCT course management system (from connections to the hardware system) for automatic grading and review.
\end{abstract}

\section{Background}

Engineering students are typically running multiple applications while simultaneously using browsers, instant messaging and search engines on their computers. This modus operandi results in competition for the user's attention and impedes the ability to focus - with the notable exception of the engrossment involved with a computer game. ${ }^{1,2}$ Consequently, the shortened attention spans, lowered tolerance for repetition, and dependence on computers seriously challenges educators to provide information in more dynamic, compelling, thorough, and interactive ways. ${ }^{3}$

As designs have become increasingly complex and electronic in nature, companies must deal with the issue that the jobs which support today's products require advanced hands-on skills in science, math, engineering and technology. ${ }^{4} 5$ Shortened attention spans impede students from staying engaged and focused in math and science classrooms, resulting in poorer performance and diminished interest in pursuing technical careers. ${ }^{2,6}$ Although there is a rising demand for electrical and electronic goods, foreign competition for electronic products and increasing use of engineering services performed in other countries are negatively impacting employment growth in the U.S. In contrast, the number of graduating engineers in other countries is on the rise - now placing the U.S. behind China, Japan and India. ${ }^{7}$ 
Notwithstanding the recent advances in educational technology, we need to incorporate more dynamic, hands-on opportunities to reach and motivate more diverse populations. ${ }^{8}$ Today's engineering students don't enter college with the same amount of hands-on experience that prior generations exhibited. We need to encourage and foster students' desire to "tinker" - by offering opportunities to physically examine their results from analysis, homework assignments and design efforts. ${ }^{9}$ We can foster scaffolding and help improve the retention of information using interactive multimedia and computer-based instrumentation, since users can guide themselves through the materials and ultimately tinker at their own pace and level. ${ }^{10,11,12}$

\section{Goals and Objectives}

Rensselaer's vision is for students to have: immediate access to course materials, educational resources, and interactive learning modules; ubiquitous Internet connectivity; and the ability to communicate and collaborate with anyone, from anyplace, at anytime. Rensselaer is Princeton Review's “America's Most Connected Campus", with many of our buildings also equipped with wireless LANs; which are typically used for file server access and communication (e.g. email, IM, etc.). We have begun to investigate how we can integrate un-tethered connectivity and mobile technology in the classroom for courses and the overall education process.

Our goal is to expand the engineering studio pedagogy pioneered by Rensselaer by in the early 90 's to have students learn with technology in more conducive physical environments - that are no longer restricted by physical or network access to specific locations. Studio-based learning has been adopted by an increasing number of universities and colleges worldwide over the past decade. It offers an innovative learning environment that, unlike traditional classroom-based lectures, enables students to be actively involved throughout the learning process. ${ }^{13,14}$ Studio classrooms are both in high demand and in extremely short supply. Configuring a studio facility typically requires a large equipment allocation/expense and a specific space utilization plan. Renovation of existing facilities may be cost-prohibitive for many schools, thus limiting their potential to leverage the aforementioned advantages that the studio format offers. A Mobile Studio can be set-up and removed in minutes, allowing for greater efficiencies in space utilization, scheduling (over a period of 24 hours/day), maintenance/support, enhanced studentteacher engagement and ultimately, improved student learning. ${ }^{15}$

Student access to user-friendly, computer-controlled instrumentation and data analysis techniques can transform the way measurements are made, allowing nearly instantaneous comparison between theoretical predictions, simulations and actual computer-based experimental results. ${ }^{16}$ Industry-standard engineering design, programming and simulation tools (PSpice, LogicWorks, Maple, etc.) allow us to fully integrate simulation/testing and compare/contrast students' predicted, analytical, and empirical results in the same learning environment. Therefore, our objective is to create a mobile laboratory environment that can: 1) eliminate the boundaries between the theory and fundamentals provided in a lecture using interactive multimedia; 2) give students an opportunity to visualize difficult concepts via hands-on explorations and electronic collaboration; and 3) enable hands-on investigation of scientific/engineering principles, devices, and computer engineering systems that have historically been restricted to specific laboratory facilities. 


\section{Project Overview}

Rensselaer has embarked upon an effort to put computing technologies into all of the lecture facilities, studio classrooms, and the student dorms \& facilities. However, a key step involves the development of new technology-based educational materials and pedagogy to provide students with further hands-on experiences that help solidify the "big ideas" and design insight associated with science \& engineering. With the help from a Hewlett Packard (HP) educational grant (that provided Tablet PCs and a mobile wireless computing environment) and state-of-the-art components and support from Analog Devices, we have begun to examine the potential for creating an instrumentation-based, Mobile Studio Tablet PC Laboratory (TabLab). The TabLab has been designed to be flexible, re-configurable, and location independent (e.g. anywhere on/off- campus). With the advent of wireless technologies, collaborative learning milieu can now extend from the campus classrooms - to the dorms - and the rest of the university spaces (e.g. the union, exercise facilities, etc.). Therefore, we have begun to offer access to instrumented setups which replicate the functionality of current Studio instrumentation (shown in figure 1). These setups provide students with the ability to perform experiments outside of the laboratory facilities allowing them to take real-world measurements utilizing Rensselaer-designed instrumentation that replicates the functionality of an oscilloscope, function generator, and multimeter. Students can now use the Tablet PCs and the USB-connected instrumentation suite (shown in figure 2) to examine and test prototype computer-controlled project designs from anywhere, at anytime.

\section{Current Studio Instrumentation Set}

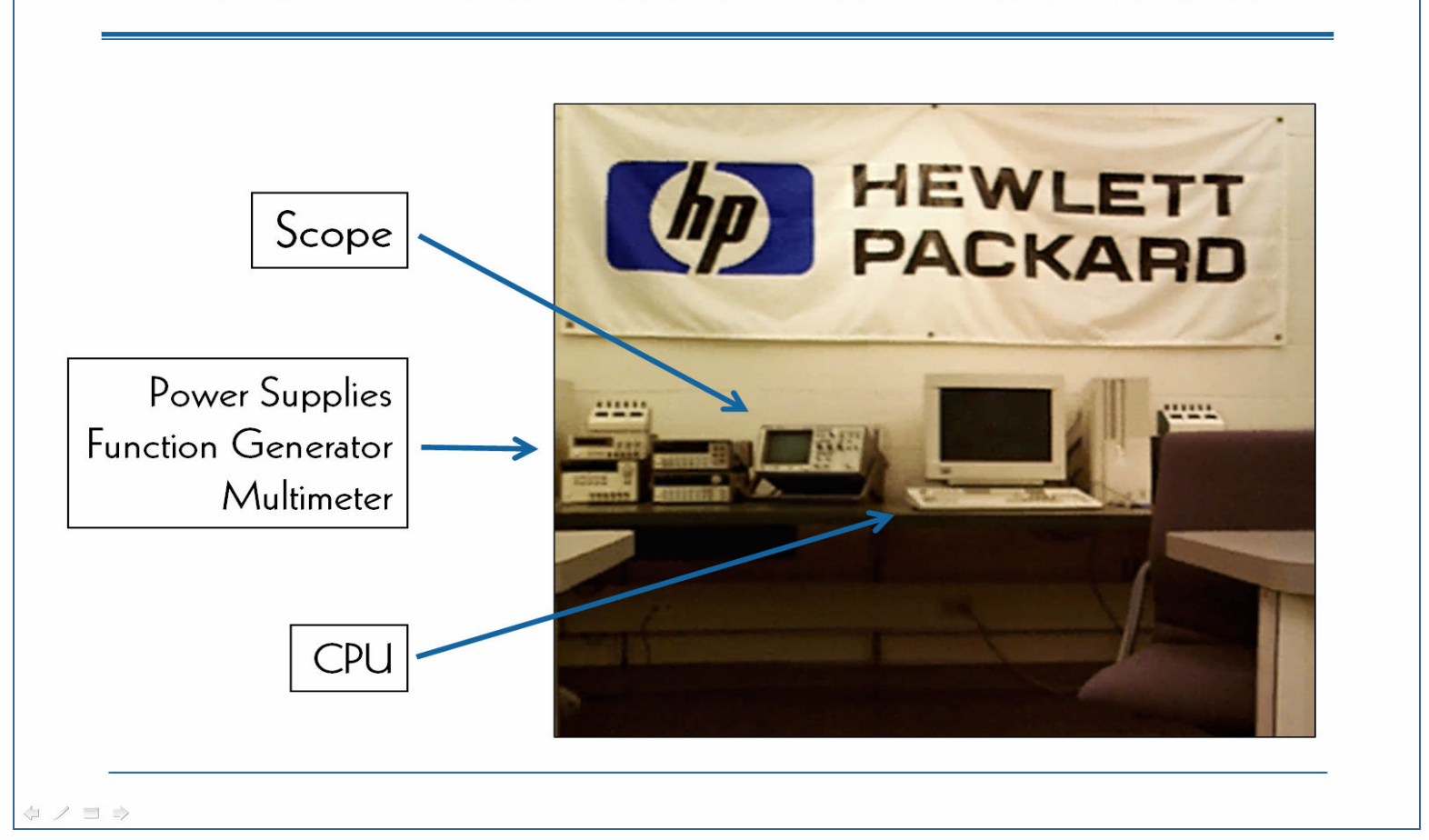

Figure 1 - Current Studio Instrumentation Setup 
The TabLab gives each student the opportunity and the equipment to learn the fundamental concepts associated with engineering education by acquiring, using and controlling real world phenomena such as: sensing parameters (position, temperature, intensity, etc.), moving objects to precise locations, and developing systems to monitor/process/manipulate events. Overall, we want to simultaneously stimulate a student's multiple senses to produce a deeper understanding of the educational concepts - hopefully leading to a greater ability for retention and use of the knowledge garnered. In addition, student access to user-friendly, computer-controlled instrumentation and data analysis techniques can change the way students make measurements, allowing nearly instantaneous comparison between theoretical predictions, simulations and actual experimental results.
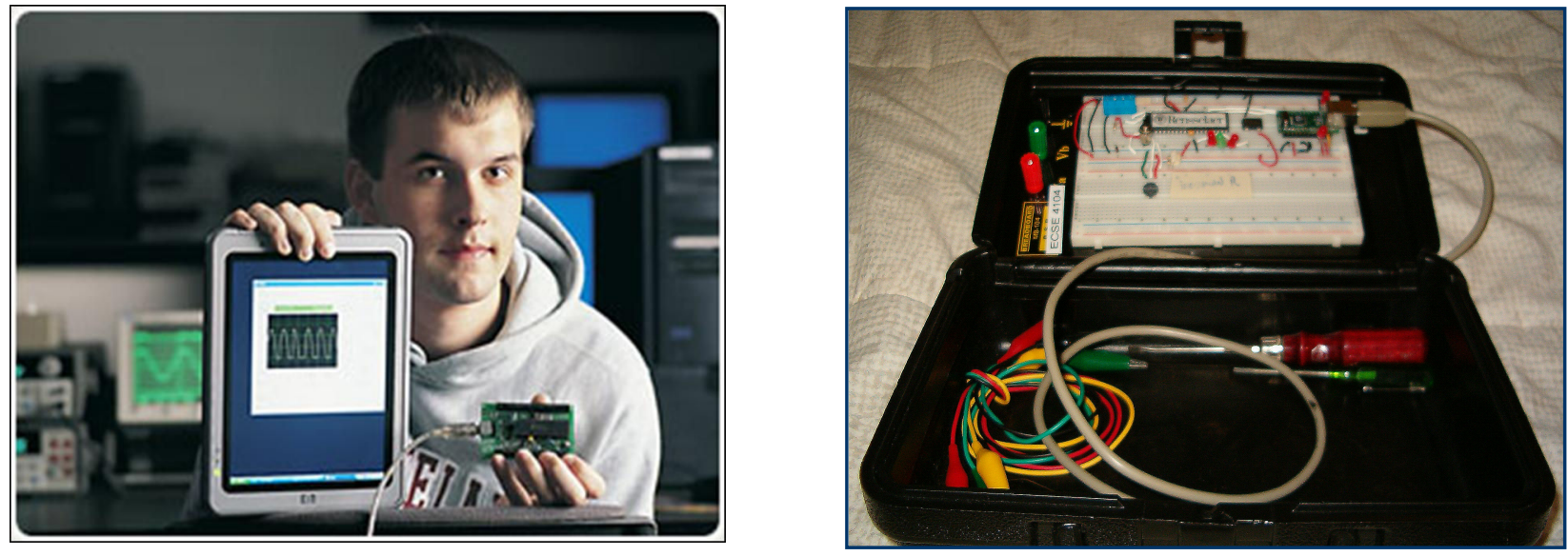

Figure 2 - Mobile Studio Instrumentation Environment

(Left: PCB version, Right: protoboard version)

Project developments will be tested and evaluated in diverse situations (similarly to the process performed in many prior NSF projects): in courses offered at Rensselaer, Howard University and at Hudson Valley Community College. The diverse testing situations will yield key information on the relative success of the project, and will contribute to further refinement/development of the materials and exhibits. Evaluators from the Evaluation Consortium (located at the University at Albany) will help assess the project and its implementation effect. The Evaluation Consortium serves as a training practicum site for graduate students in the field of program evaluation and is active in the design and implementation of innovative evaluation methodologies at the regional, national and international level.

The assessment team is focusing on identifying intermediate success, programmatic weakness and areas in need of modification or alteration as the TabLab materials, projects, and related programs are developed, implemented and fully tested. Summative evaluation is focusing on short-term and long-term learning, transfer of knowledge to other courses, and transfer of ability to use the instrumentation across content. Data is being collected from students, faculty, students and other educators using the mobile studio technologies. The project will additionally be evaluated by tracking student's success in subsequent course work, in conjunction with ABET institutional program assessment. This effort has the potential of showcasing the results of this 
effort on a national level by involving various student populations - in addition to the high national/global interest in the SMET related content covered in the project.

\section{Project Activities}

The full project's development activities and anticipated deployment/dissemination outcomes (listed in Table 1) will be completed over a period of 1.5 years, with approximately $20 \%$ of the efforts completed at the time of this writing. A project team of educators, researchers and developers has been assembled to develop the curriculum, evaluation criteria, and achieve the desired outcomes. Academy of Electronic Media (www.academy.rpi.edu) personnel have collaborated with content experts from Rensselaer and Howard University to design and develop the prototype materials and Tablet PC based instrumentation activities.

\section{Development}

Prototype low frequency Tablet PC based-signal acquisition system

Develop signal generator, sensor interface, and DMM functionality Develop full-range Tablet PC based-signal acquisition and control system (with $4 \mathrm{~A} / \mathrm{D}$ \& D/A, 10 digital I/O, 2 PWM and 2 arbitrary waveform generator ports)

Develop 5 interactive projects/ experiments that utilize the Mobile Studio hardware Create 5 design scenario challenges that illustrate variations between virtual (ideal) and physical (non-ideal) Develop system to directly import user data/values into course management system for automatic grading (WebCT)

Develop supporting K12 programs and museum exhibit(s)

\section{Deployment}

Provide open access to the interactive modules, experiments, class notes and design challenges via the web Integrate materials in the Engineering curricula (at RPI, Howard and Hudson Valley Community College)

Instructor collaboration program with:

○ RPI $\leftrightarrow$ Howard University (Engineering. Science)

- RPI $\leftrightarrow$ HVCC Pre-engineering program (Circuits., Electronics)

Adapt and use signal acquisition and control hardware with interactive learning materials in other studio courses (Core/ Introductory Engineering) Produce instructor course materials
Evaluation

Instrumentation utilization analysis Faculty interviews Instructional technology review

Pre-project assessment, classroom and dormitory based observation of hardware/software module utilization Student surveys \& interviews Usability review (in conjunction with onsite classrooms, student facilities (Union) and dorms)

Project success metrics analysis Website review and assessment Formative/summative assessment of learning outcomes K-12 outreach programs \& museum exhibit satisfaction surveys

\section{Dissemination}

Full scale production of instrumentation system's circuit board and interface circuitry (probes, power supplies, signal connectors, USB circuitry, etc.) PKAL and NSF Chautauqua workshops (2005, 2006)

ASEE 2005/2006 (project overview \& initial results, final implementation review) IEEE - FIE 2005/2006 (work in progress, final report)

ICEE - 2005 (project overview)

Begin to build partnerships with other:

○ Universities, community colleges, technical inst., and $\mathrm{K}$ 12 entities

- Training programs

- Museum programs/exhibits Investigate incorporation of materials and system into textbook publishers' offerings (e.g. websites) 


\section{Initial Pilot Testing}

Prototype materials and hardware were piloted and evaluated in a Network Analysis II class at Howard University (EECE 301) on December 2, 2004 in coordination with a class project which was historically offered without a physical implementation segment to the effort. Prior to the pilot TabLab session, students were given a project assignment to design, analyze and examine (using PSpice) an op-amp based treble control circuit (as shown in Figure 3). The students were asked to derive the transfer function $\mathrm{H}(\mathrm{s})=\mathrm{V}_{\text {out }}(\mathrm{s}) / \mathrm{V}_{\text {in }}(\mathrm{s})$, find the cutoff frequency, draw the Bode plots, and analyze the circuit (with specific values for the R's and C) using PSpice for a number of values of $\beta$ (corresponding to various potentiometer positions). The assignment was turned in prior to the pilot TabLab oriented circuit development experience and evaluated separately from the hands-on component.

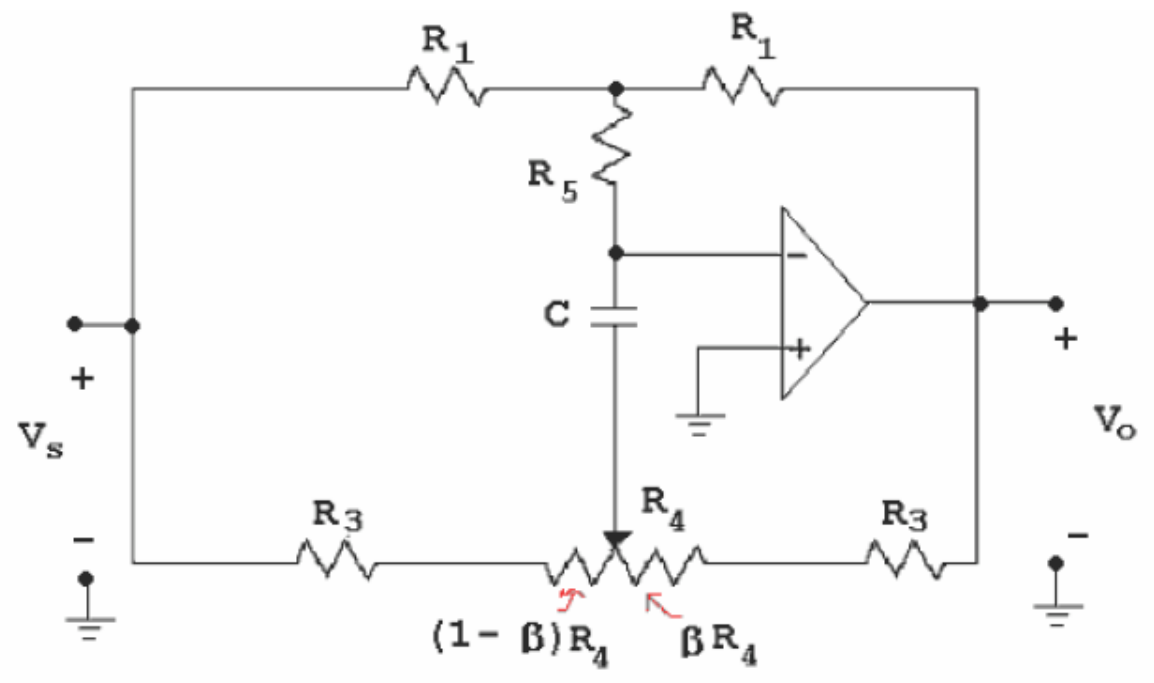

Figure 3 - Project Treble Control Circuit

Howard University does not currently have any studio-oriented facilities or courses that combine lecture, labs and problem sessions in a single environment. The pilot was carried out in a makeshift studio space that is typically setup as an instrumented laboratory. The mobile studio environment used a combination of fold-up tables/chairs (shown in Figure 4) and a wireless network to provide access the project materials. The students who were enrolled in the Network Analysis II class were asked to voluntarily participate in the pilot study, which was carried out one day after the formal class ended. Only one of the students out of the total enrollment did not participate in the study, due to a scheduling conflict. When queried as to why we experienced such an exemplary turn-out (20/21 students), the typical response involved a strong desire to "experience" their designs in operation.

The pilot activity was organized and the mobile studio room was set-up in a 40 minute period from 7:20am to 8:00am. The pilot studio class (depicted in figures 4 and 5) began at 8:00am with a 30 minute overview of the activity (incorporating a "Filters CAD" module from the Academy of Electronic Media's website: http://www.academy.rpi.edu/projects/ccli/, as depicted below in figure 6) along with a demonstration of a working circuit (using an electric guitar as the input 
signal) in conjunction with an audio amplifier. The self-selected teams of students (10 teams, with 2 students/team) were then allocated approximately 90 minutes to construct and test their designs using the protoboard version of the instrumentation system and a Tablet PC (shown in figure 2).

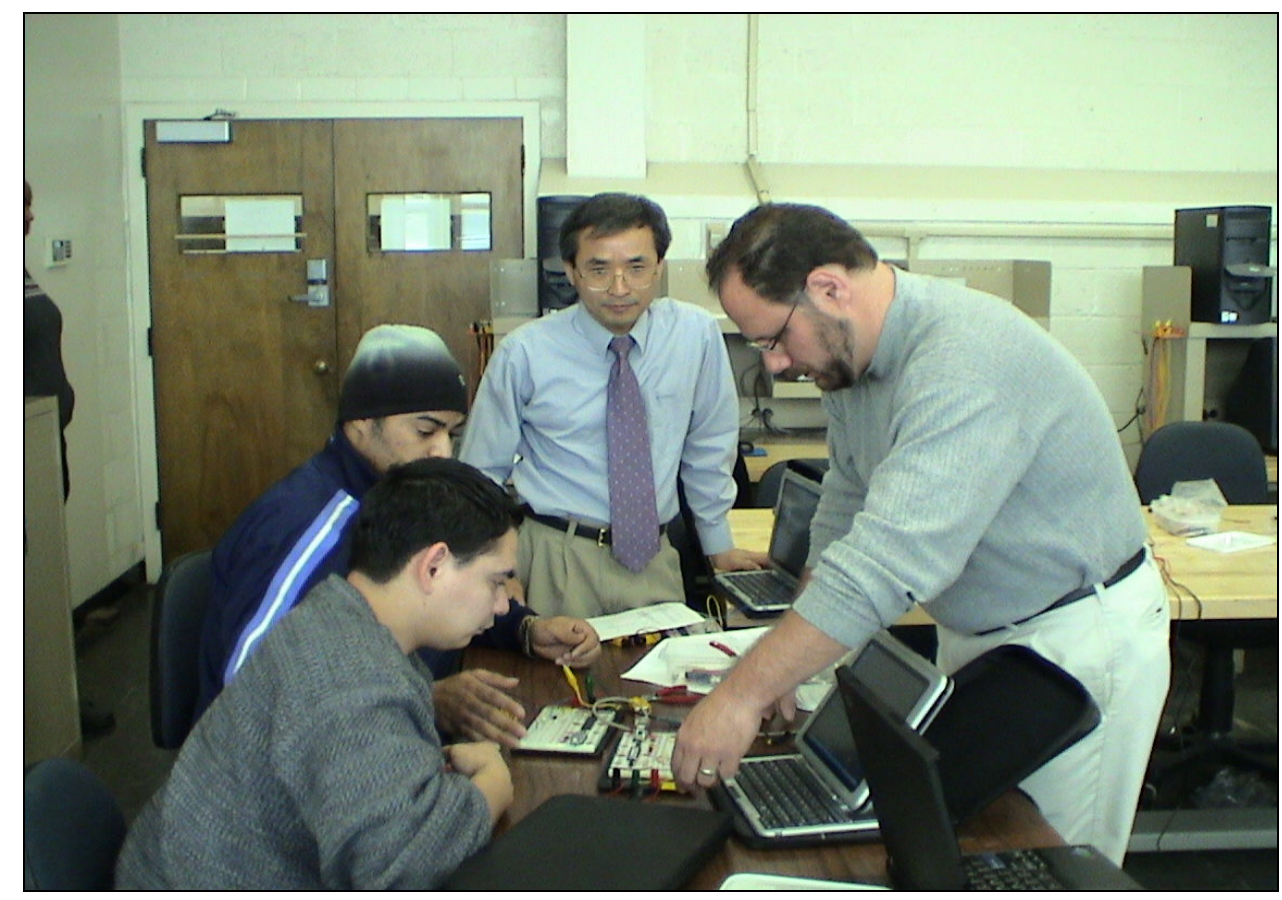

Figure 4 - Mobile Studio Classroom Setup at Howard University

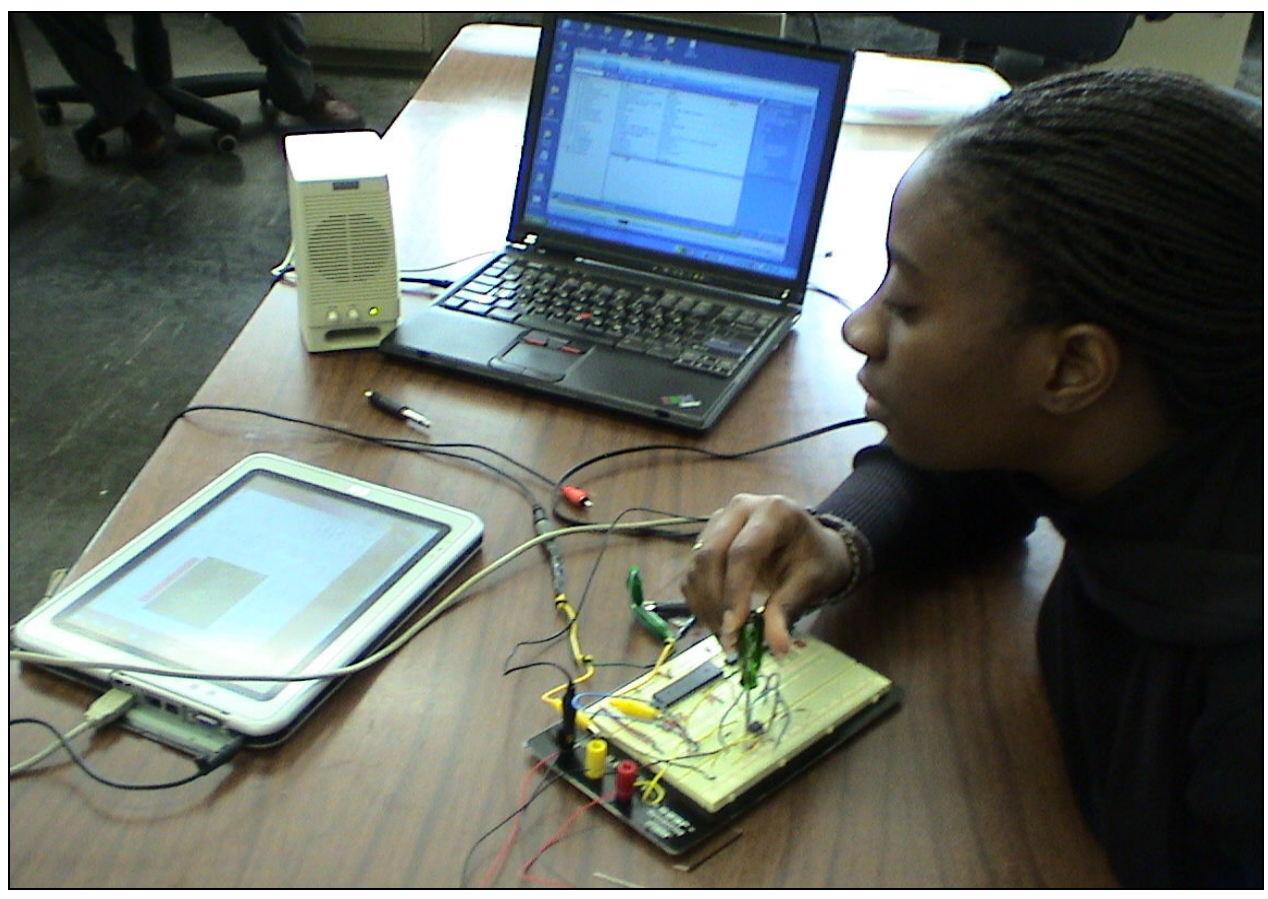

Figure 5 - Testing a Circuit Design Using the TabLab

"Proceedings of the 2005 American Society for Engineering Education Annual Conference \& Exposition Copyright (C) 2005, American Society for Engineering Education" 
All of the teams created protoboard versions of the treble circuit and tested them with the instrumentation, while $6 / 10$ were able to successfully demonstrate a functional circuit (altering $\beta$ by turning a potentiometer) via utilizing the media player of the Tablet PC as an input and connecting the circuit's output to an amplifier/speaker to listen to the corresponding filtering effect. Unfortunately, a number of the students had additional commitments at 10:00am and had to leave before they were capable of testing their circuits. The course director (Dr. Charles Kim) further observed that his students remained fully engaged up until the last possible minute - prior to their subsequent commitments.

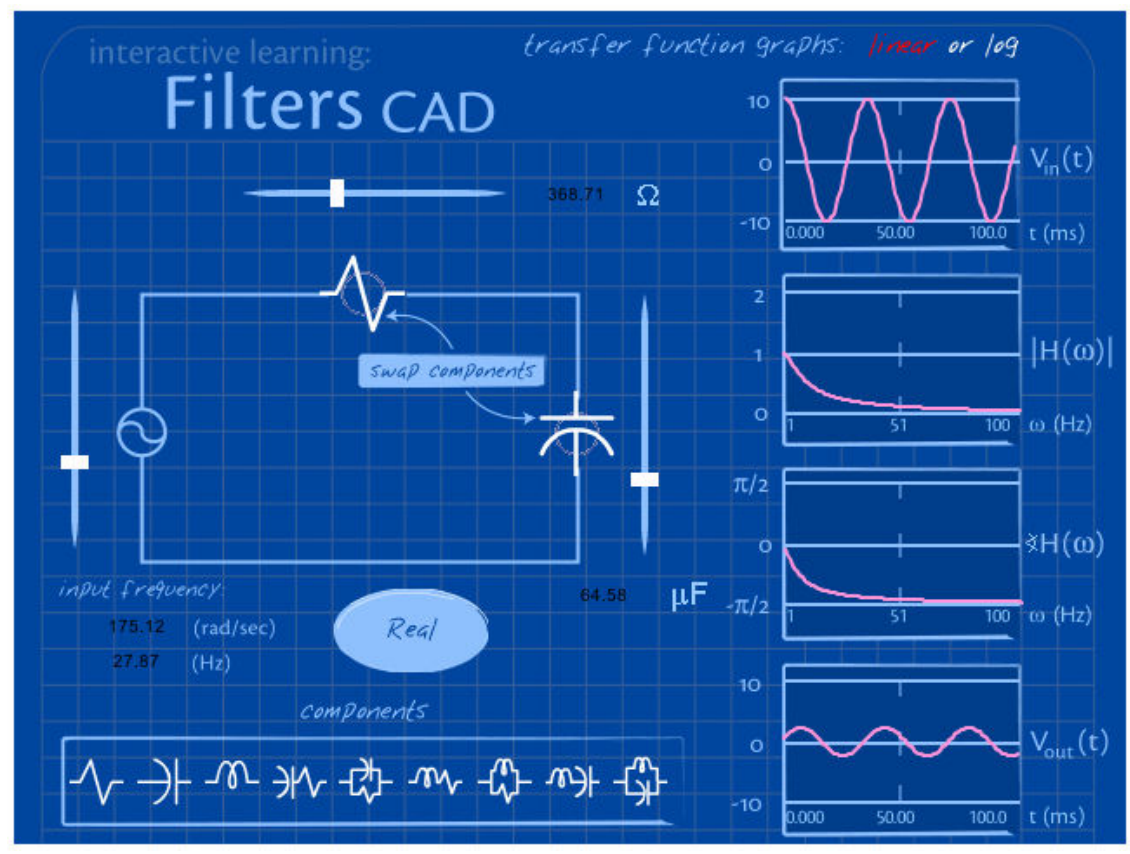

Figure 6 - Filters CAD Module Sample Screen

As a part of the overall assessment effort, the students were asked to respond to the following survey questions after participating in the pilot activity:

1. What did you like most of the mobile studio class?

2. Do you think your understanding for the treble volume control circuit that you worked for your project is reinforced by attending the mobile studio class?

3. Do you feel now that you have some connection between analysis of frequency selective circuit and its action in real world situation?

4. Do you like to see more of this kind class (lecture + lab combination) without heavy equipment?

5. If I plan to bring this kind of mobile studio class (in a much reduced version) to Network Analysis I or Network Analysis II, which subject(s) would be the best candidate to be performed by this? Select the subjects from the following list: KVL \& KCL, Node voltage \& Mesh Current, OP Amp circuit, Inductors and Capacitors, First order circuits (RC and LC), second order circuits (RLC), Passive Filters, Active Filters, Steady State Sinusoidal Analysis). 
6. In addition to Network Analysis, which course(s) would be most benefited by the mobile studio class?

7. What improvement did you feel we have to make for a better mobile studio class?

Response to the pilot activity was overwhelmingly positive. All of the students felt that there was great value in having mobile studio environments and felt their understanding of the Network Analysis concepts were enhanced by the activity. One of the students immediately sought out the electrical and computer engineering department's chairman to request that such efforts be coupled to all of the courses offered. Students were extremely pleased with the instrumentation and the visualization opportunity, providing further impetus for the course instructor to plan for two similar projects - involving design, development and testing experiences to be incorporated into the spring 2005 Network Analysis I course offering (e.g. addressing Op Amps and $2^{\text {nd }}$ order RLC circuits).

\section{Preliminary Conclusions and Future Considerations}

We hope to further explore the use of Tablet PC technologies in an attempt to better accommodate the particular learning styles of individual students through a combination of teambased laboratory design activities and student-centered collaborative learning environments. ${ }^{17}$ The students will ultimately not have to totally rely on the in-class experience, the teacher, and/or associated book(s) to gain a deep understanding of the material or perform experimentation. Overall, we hope to reduce the potential for students to become isolated and help address the declining number of U.S. students entering STEM oriented fields through the creation and dissemination of practical educational materials to re-engage and inspire today's student population.

We also plan on further leveraging interactive learning materials (http://www.academy.rpi.edu) by integrating both virtual and physical experiments using Tablet PCs to help provide a context for engineering education and address the difficulties associated with empirical learning today. ${ }^{18}$ Typical collaborations (student-student, student-teacher) in engineering classes are typically limited to using static 2D data (e.g. on paper) and constrained problems. This pilot project has allowed us to utilize dynamic data (using real-time experimentation), collaborative pedagogical practices, and in-class design scenarios to further engage students and ultimately, make their educational experience more memorable and enjoyable.

\section{Bibliography}

1. $\quad$ Felder, R., "The Warm Winds of Change." Chem. Engr. Education, 30(1), 34-35, Winter 1996.

2. Christakis D.A., Zimmerman FJ, DiGiuseppe D.L., McCarty C.A. Early television exposure and subsequent attentional problems in children. Pediatrics. 2004; 113:708-713.

3. Kirriemuir, J. A Survey of the Use of Computer and Video Games in Classrooms. Internal report for Becta (British Educational Communications and Technology Agency). www.becta.org.uk/, 2002.

4. Drum, C., Earle, J., Suter, L., and VanderPutten, E. "Math \& Science Improvements Still Needed in Middle School, Repeat Study Shows," Third International Mathematics and Science Study Repeat (TIMSS-R), NSF PR 00-91 (http://www.nsf.gov/od/lpa/news/press/00/pr0091.htm) - December 5, 2000. 
5. Weiss, I.R., Banilower, E.R., McMahon, K.C., and Smith, P.S. Report of the 2000 National Survey of Science and Mathematics Education. Chapel Hill, NC: Horizon Research, Inc., 2001.

6. Iris R. Weiss, Joan D. Pasley, P. Sean Smith, Eric R. Banilower, Daniel J. Heck "Looking Inside the Classroom: A Study of K-12 Mathematics and Science Education in the United States," Horizon Research, Inc., (http://www.horizon-research.com/insidetheclassroom/reports/looking/complete.pdf) May 2003

7. Board, W. J., "The US is Loosing Dominance in the Sciences," New York Times, May 3, 2004.

8. Colwell, R. (2004) "The Emerging Science of Learning", Presentation at the Institute for Human and Machine Cognition, University of West Florida, Pensacola, Florida, January 21, 2004.

9. Bransford, John. D, A. L. Brown, and R. Cocking, eds. "How People Learn," NAC Press, Washington, D.C., 1999.

10. Linn, M.C. 'Designing Computer Environments for Engineering and Computer Science: The Scaffolded Knowledge Integration Framework, Journal of Science Education and Technology, Vol. 4, No. 2, 1995.

11. Vygotsky, L. (1934/1986). Thought and Language, trans. A. Kozulin. Cambridge, MA: Harvard University Press.

12. Hillocks, G. (1999). Ways of Thinking/Ways of Teaching. New York: Teachers College Press.

13. Maby, E.W. Carlson, A.B. Connor, K.A. Jennings, W.C. and Schoch, P.M., "A Studio Format for Innovative Pedagogy in Circuits and Electronics", Proceedings of 1997 Frontiers in Education Conference, Pittsburgh, PA, November 1997.

14. Holmes, M., "Breaking down traditional disciplinary boundaries in the classroom," Selected Papers from the 13th International Conf on College Teaching and Learning, 75-96, (J. Chambers, ed.), FCCJ, Jacksonville, 2002.

15. D.A. Kolb, Experiential Learning: Experience as the Source of Learning and Development. Englewood Cliffs, NJ, Prentice-Hall, 1984.

16. Hagler, M., "Laboratory Exercises for Analog Circuits and Electronics as Hardware Homework with Student Laptop Computer Instrumentation", International Symposium IGIP / IEEE / ASEE 2004, September 27-30, Fribourg, Switzerland.

17. R.M. Felder and L.K. Silverman. "Learning Styles and Teaching Styles in Engineering Education." Engr. Education, 78 (7), 674-681, 1988.

18. Millard, D., Burnham, G., "SMET Learning Modules for an Electronics Curriculum" (DUE - 9950356) Final Report, National Science Foundation, June 2002.

\section{DON LEWIS MILLARD}

Dr. Millard directs the Academy of Electronic Media at Rensselaer (2003 Premiere Award Recipient) and has authored numerous university and K-12 educational materials for mathematics, science, engineering and arts courses that are regularly accessed by a global population. He has participated and served as the PI on many research efforts, including NSF, DARPA, DoD and corporate-sponsored projects. 